\title{
Covid-19: An Impromptu or Trend-setting Factor in Research on Language and Education?
}

\author{
Lilia Raitskaya ${ }^{1}$, Elena Tikhonova ${ }^{2,3}$ \\ ${ }^{1}$ Moscow State Institute of International Relations (MGIMO University) \\ ${ }^{2}$ Moscow State University of Food Production \\ ${ }^{3}$ National Research University Higher School of Economics \\ Correspondence concerning this article should be addressed to Elena Tikhonova, National Research \\ University Higher School of Economics, 26 Shabolovka, Moscow, Russian Federation, 119049. \\ E-mail: etihonova@hse.ru
}

\begin{abstract}
With the flood of research on Covid-19 in 2020 and 2021, pandemic-induced emergency is giving rise to new unprecedented challenges for all strata of the society, including science and education. The JLE editors focus on the first outcomes and hurdles the pandemic-caused research publishing has led to. The authors dwell upon the research on education in the context of Covid-19 constraints with a special accent on higher education and L2 teaching, considering the key trends as a response to the gaps in the field knowledge. Some attention is paid to emerging linguistic research and new word coinages to define the new phenomena. The editors summarize the obstacles that "fast-track" publishing and shortened peer review have built up, suggesting some estimates as of the Covid-19 effects of the research avalanche for science.
\end{abstract}

Keywords: Covid-19, higher education, emergency remote teaching, emergency publishing, neologisms

\section{Covid-19 Effects: Setting the Stage}

Starting with the outbreak of the novice Covid-19 infection, in addition to the human toll it causes, the world has been facing significant material and non-material losses elsewhere. Though, the magnitude of the losses is still uncertain, as some indirect consequences may follow this watershed period for the humanity with some delay. Many aspects of human life will never be the same. Disruptions caused by the Covid-19 pandemic are multiple across different sectors and areas of life (Reimers \& Marmolejo, 2022). The pandemic impeded, accelerated, or accentuated the previously existed trends and societal problems (Ahlburg, 2020).

Journals and publishers throughout the world "claimed unprecedented volumes of journal submissions and published articles"1 in 2020. The rise has further accelerated in 2021. Research in medicine accounts for the bulk of the avalanche submissions. The Covid-related growth in publications is essentially fuelled by medical research on Covid-19. According to Dimensions ${ }^{2}$, the world's largest linked research information dataset, covering $122 \mathrm{~m}$ publications across all research fields, the skyrocketing growth in medicine research resulted in 412,221 publications; 20,282 datasets; 13,182 grants; 2,291 patents; 13,459 clinical trials; and 7,291 policy documents for both 2020 and 2021 (as of November 30, 2021). The major fields of research include Medical and Health Science $(219,808)$, Public Health and Health Services $(105,528)$, and Clinical Sciences $(71,548)$. The total citations of the above documents worked out at 1,247,780 and 2,190,704 in 2020 and 2021 respectively.

The estimates are based on "Covid-19" as the keyword search enquiry and limited by the publication period of 2020 and 2021 (incomplete data). The second search was conducted on the keyword "Covid-19 and education" enquiry, showing 24,664 publications (of which 8,901 in 2020, and 15,743 in 2021 - incomplete data). The most

\footnotetext{
https://scholarlykitchen.sspnet.org/2020/11/19/guest-post-scientific-output-in-the-year-of-covid/

2 All statistics in this section are borrowed from http://app.dimensions.ai(as ofDecember 2, 2021in response to the search enquiries "Covid-19" and "Covid-19 and education").
} 
prolific authors (2020-2021) were Muhlasin Anrullah with 31 publications; Daisy E. Fancourt with 21 articles, Andrew Patrick Steptoe with 15 publications.

The fields of research embrace Medical and Health Sciences (9,632); Education (9,218); Specialist Studies in Education (8,732); Public Health and Health Services (7,450); and Curriculum and Pedagogy $(3,237)$. The total publications $(24,664)$ were categorized as 20,237 articles; 1,990 preprints; 1,312 proceedings; 974 book chapters; 120 edited books; and 31monographs.

The leading source titles include SSRN Electronic Journal (558); medRxiv (440); International Journal of Environmental Research and Public Health (296); JMIR Preprints (261); Sustainability (221); PLOS ONE (188), and others. Open access (OA) has become the prevailing form of publications in 2020-2021, with 19,350 open access research out of 24,664, including Gold OA (9,952), Closed OA (5,314), Bronze $(4,390)$, Green $(2,753)$, and Hybrid (2,255). The Covid-19 situation has obviously encouraged open access and preprint proliferation. Citations of the Covid-19-related educational research had reached 93K by December 1, 2021.

\section{Figure 1}

Publications and Citations of Research on Covid-19 Impact on Education

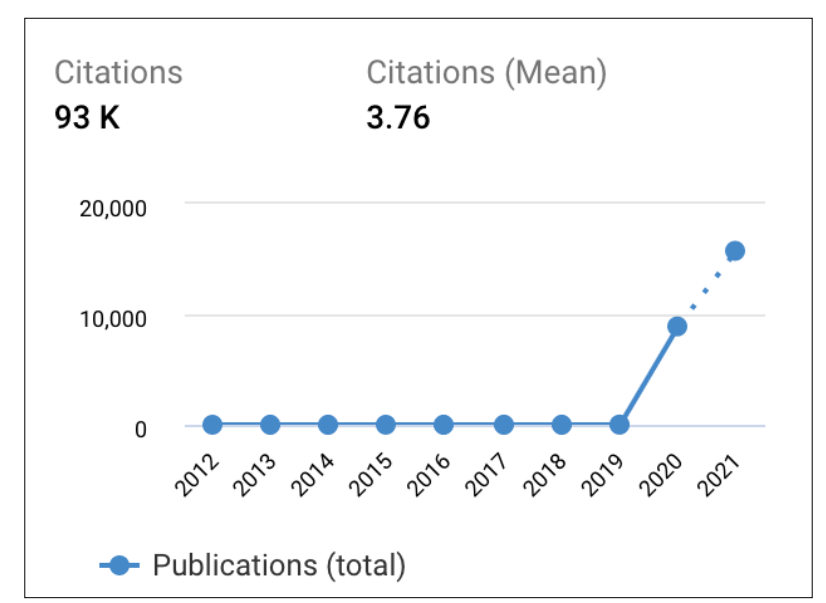

Source: Dimensions Data Platform, as of November 30, 2021.

The publication trends and patterns found on the Dimensions platform are supported by those in the Scopus database. The total number of publications on Covid-19 in both 2020 and 2021 worked out at 230,109 as of December 4, 2021. 178,580 publications out of 230,109 are open access of all types. The breakdown of the publications shows the same prevailing fields of research: Medicine (141,584 publications), Social Sciences (32,006 publications), and others. The most frequent affiliations include Harvard Medical School (3,234 publications), the University of Toronto (2,339 publications), Inserm - the National Institute of Health and Medical Research, France (2,205 publications), Oxford University (2,112 publications), and Huazhong University of Science and Technology (1,928 publications). The research geographically spreads among the USA (57,395 publications), the UK $(23,646)$, China $(21,462)$, Italy $(18,174)$, India $(16,634)$, and other countries with fewer than 10,000 publications each.

The search on "Covid-19 and education" in the Scopus database brought 20,173 publications $(5 ; 6,845 ; 13,210$; and 113 publications in 2019, 2020, 2021, and 2022 respectively) on December 3, 2021. The bulk of the articles were published in the fields of Medicine (9,969 publications), Social Sciences (6,796 publications), and Computer Sciences (2,364 publications). The journals, leading by the number of the publications on the Covid-19 impact on education, are Sustainability Switzerland, Education Sciences, and Academic Medicine.

\section{Educational Landscape}

Though the sector of education is beyond the matters of life and death, it was severely affected by disruptions and lockdowns. The emergency shift of the teaching and learning to the online platforms took enormous effort 
of all the parties concerned (teachers, faculty, administration, and students). To alleviate the effects of the pandemic, universities had to comprehensively respond to the educational landscape formed in emergency, to address challenges ranging from the societal constraints to student disengagement with learning, and to fill up the skill gaps facilitating independent learning and remote teaching. The research focus in the field of education, thus, has been following the needs to fill up the gaps connected with online didactics competencies, psychological adaptation of students and occasionally teachers to the virtual classroom, new efficient forms of online assessment. Some fresh new topics have emerged (emergency remote teaching and learning; new approaches to online assessment; teacher engagement and emotion regulation in coping with stress caused by online teaching).

Semanticscholar.org ranges the most influential publications, outlining highly influential citations identified by "utilizing a machine-learning model analysing a number of factors including the number of citations to a publication, and the surrounding context for each". ${ }^{3}$ The article scored most in this category (with the total citations of 652, including 55 highly influential citations as of November 30, 2021) is headlined "Covid-19 and online teaching in higher education: A case study of Peking University" (Bao, 2020). The article overviews six prevailing instructional strategies based on "high-impact principles of online education" (Bao, 2020, p.113). It took universities days to transfer their face-to-face courses and materials online, with faculty members, lecturers, professors, and students being essentially deficient in some online skills. The research attracted much attention as it became of the earliest published papers (accepted for publication March 20, 2020) focusing on the more or less successful instructional online strategies in the tertiary institutions.

\section{Educational Research: Tackling the Pandemic Challenges}

This editorial does not aim to make a detailed in-depth review of the publications on the Covid-19 impact on education. Anyway, we have examined a range of the relevant research published in 2020 and 2021 and found that there are clear-cut topics of interest across the educational aspects of the pandemic. As JLE tends to stay within its scope, we have focused on higher education issues, L2 and EFL teaching, psychological aspects of adaptivity to emergency remote learning and teaching, technology-driven language teaching during a pandemic, online assessment in education, especially in language learning. The most of the research agenda is not brand-new. To be precise, it looks like revisiting many interrelated topics in the context of emergency shift to new patterns of teaching and learning.

During the pandemic, universities arose as the centres engaged in conducting comprehensive research aimed at filling the knowledge gaps as far as emergency remote learning and teaching are concerned. Secondary schools do not have enough resources and competencies to take up the issues independently on their own.

Teaching L2 and foreign languages has been tackled as a separate and specific area with its unique approaches in the following research fields and sub-fields and selected sample publications:

(1) emergency teaching and learning languages with technology during a pandemic, including emergency remote teaching and learning (Charania et al., 2021; Cheung, 2021; Choi \& Chung, 2021; Hazaea, Bin-Hady \& Toujani, 2021; Ionela, 2020; Levina, Zubanova \& Ivanov, 2021; Moser, Wei \& Brenner, 2021);

(2) online assessment in teaching languages (Abrar-ul-Hassan, Douglas \& Turner, 2021; Mahapatra, 2021);

(3) psychological challenges, adaptivity, learner and teacher autonomy, student engagement and motivation, teacher stress and coping (Almusharraf \& Khahro, 2020; Resnik \& Dewaele, 2021; Gregersen, Mercer \& MacIntyre, 2021; Heydarnejad, Zareian, Ghaniabadi \& Adel, 2021).

\section{Defining New Phenomena: Research on New Word Coinages and Usages}

All major fateful periods in human history always give rise to new word coinages and usages in all world languages to reflect the emerging phenomena and attendant circumstances. The pandemic broke out in the

\footnotetext{
${ }_{3}$ https://www.semanticscholar.org/faq\#influential-citations
} 
time of worldwide access to linguistic big data that registered a simultaneous and synchronized inflow of the new words and new meanings into almost all languages.

The most impressive influx was registered as early as the first four-six months from the beginning of the pandemic. The Oxford English Dictionary regularly contributes updates to the dictionary, with some 100-500 entries every 2-4 months. The year of 2020 was not an exception. It is surprising that really new coinages in English were few (Covid-19, covidiot, covident). Most of the updates to the Oxford dictionary covered words with new connotations. You will find below an abridged list of the neologisms, new connotations of the existing words, frequently used words and phrases related to or associated with the Covid-19 pandemic. Where appropriate, we state the years, when these words or phrases were originally or repeatedly registered in the discourse (see the brackets).

An Abridged List of the Covid-19 Related Neologisms, New Connotations, and Frequently Used Words (Phrases) ${ }^{4}$

\section{Words \& Phrases with New Connotations}

coronavirus $(1968 ; 2008)$

SARS "severe acute respiratory syndrome" (2003)

social distancing (1957)

self-isolating (1841)

self-isolation (1834)

shelter in place $(1976 ; 1994)$

self-quarantined (1878)

infodemic (2003)

elbow bump; hand slap; high five (1981)

WFH "working from home" (1995)

PPE "personal protective equipment" (1934 as a full phrase; 1977 as an abbreviation)

New Coinages 2020-2021

Covid-195 (2020)

SARS-CoV-19 (2020)

covidiot (2020)

covidient (2021)

Frequently Used Words \& Phrases (Frequencies are measured per million tokens)

pandemic

stay-at-home

furlough

lockdown

(phased) reopening

school closure

non-essential travel

flu-like

Zoom

disinfectant

mask

face-covering

ICU "Intensive Care Unit"

telemedicine

frontline worker/ employee/ staff

\footnotetext{
${ }_{4}^{4}$ Based on the neologisms and frequently used words (phrases) collected by the researchers (Asif, Zhiyong, Iram \& Nisar, 2021; Lei, Yang \& Huang, 2021) and the updates to Oxford English Dictionary published at http://public.oed.com/updates/

5 One should note that the name of the disease is spelled as both "Covid-19" and "Covid-19". There is a clear preference of the spelling with an initial capital in British English, while American English gives preference to the word with full capitals, i.e. Covid-19. See https:// public.oed.com/blog/using-corpora-to-track-the-language-of-covid-19-update-2/
} 
It is natural that research publications on neologisms should come out amid the emerging new social and political realia. In this instance, the publications were not numerous but arouse wide public interest as they concentrated on the emerging discourse.

The trend was registered in various languages: in Polish (Cierpich-Kozieł, 2020; Jablonka, 2021); in Arabic (Haddad \& Montero-Martínez, 2020); in Portuguese (Jablonka, 2021); in Spanish (Zholobova, 2021), etc. The bulk of the new words and usages were initially formed in English and borrowed by other languages. The researchers single out metaphor-based neologisms, consider linguistic innovation during the Covid-19 pandemic, analyse the ways the lexeme "coronavirus" influences various languages.

Trending neologisms in English also became the object of study, with several articles containing a deep linguistic analysis (Al-Salman \& Haider, 2021; Asif, Zhiyong, Iram \& Nisar, 2021; Lei, Yang \& Huang, 2021; Wang \& Huang, 2021). The researchers focus on the ways the new words are coined, the spread of the new usages of the words and phrases dating back to previous epidemics or associated circumstances. A striking feature of the present-day lexical update is rather frequent use of medical terms in everyday discourse of mass media and people at large. "These terms are used widely on social media and press conferences of different medical fields globally" (Asif, Zhiyong, Iram \& Nisar, 2021). For example, they include "asymptomatic", "community spread", "flatten the curve", "ventilator", immunity", names of medicines, and others. Social media contributed much to the spread of these terms and new usages.

\section{Scholarly Publishing and Peer Review in the Context of the Covid-19 Pandemic}

Though, the medical scholarly community in China initially had an edge over their colleagues elsewhere as the Covid-19 outbreak started there, the involvement of researchers in other countries followed the way the virus was spreading (India, Europe, the USA). An analysis of publications on both Covid-19 and its impact on education shows the similar pattern, with the USA, the UK, and China being the most numerous publications (Scopus; Dimensions; PubMed).

The drive to get their research published, on authors' part, and to bring out articles written on the top priority themes, on journals' part, resulted in the flood of Covid-19 publications. It raised again the problem of critical peer reviewing, as fast-track publishing eventually induces inadequate or unfair evaluation of some research. As peer review aims to ensure that only valuable scientific contributions based on scientific methodology should be published, its shorter time and fast-track conditions might ruin unbiased review feedback. Thus, the scholarly community is inclined to suggest that open peer review should be encouraged as it is the simplest and most efficient way to evaluate new research without bias or mistake. Open peer review and Publons may promote the ethical standards in reviewing by detecting fraudulent peer reviews and fake reviewers' identities via proving digital identity verification and blocking fake reviewers' accounts (Teixeira da Silva \& Al-Khatib, 2021).

One more feature of publishing during the Covid-19 pandemic is open access and preprints. In his interview to The Scholarly Kitchen blog, Daniel Hook, CEO of Digital Science, underlines that "many publishers have made the research ... freely available through a variety of different mechanisms". ${ }^{6}$ Open access popularity is proved by the statistics of the Covid-19 publications. ${ }^{7}$ He also comments on preprints as being a "double-edged sword" with their universal access to the research content fresh from the labs. Immediate awareness of scientists of the cutting-edge research combined with open pre-publication discussion may occasionally result in misinterpretation of the research results by "general public" that has no understanding of scholarly communication. Thus, general public sometimes may come to wrong conclusions. ${ }^{8}$

In addressing old and new challenges that scholarly publishing faces, world scholarly community will have to further proceed with Open Science without delay, especially against the pandemic backdrop.

\footnotetext{
${ }^{6}$ Harington, R. (2020). How Covid-19 is changing research culture: An interview with Daniel Hook, CEO of Digital Science. The Scholarly Kitchen. https://scholarlykitchen.sspnet.org/2020/06/24/how-covid-19-is-changing-research-culture-an-interview-with-daniel-hook-ceo-of-digital-science/

Dimensions Data Platform as of November 30, 2021. Detailed information is given above (Section "Covid-19 effects: setting the stage").

8 Harington, R. (2020). How Covid-19 is changing research culture: An interview with Daniel Hook, CEO of Digital Science. The Scholarly Kitchen. https://scholarlykitchen.sspnet.org/2020/06/24/how-covid-19-is-changing-research-culture-an-interview-with-daniel-hook-ceo-of-digital-science/
} 


\section{Concluding Remarks}

The Covid-19 pandemic and pandemic-induced rather long period of constraints in social life worldwide have caused some shifts in social patterns applicable to education and scholarly publishing. Education has suffered from shifts to emergency remote teaching and a new paradigm of schooling and learning in the essentially virtual environment. The latter has become the major cause of stress and disengagement for students. With much progress in overcoming slow or delayed adaptation of students and teachers to the new virtual challenges, education at large is revisiting many concepts previously considered immutable or habitual (assessment in language learning; student and teacher engagement; teacher stress and coping; emotion regulation, etc.).

The pressure to urgently publish articles on the emergent topics resulted in the avalanche publishing, with the publishers introducing shorter fast-track peer review. The latter has led to some ill-conceived and sometimes errant publications.

The Covid-19 pandemic has generated a great inflow of new words and usages into languages throughout the world, increasing the research published on the topic.

Though still being formed, the emerging research agenda combines publishing brand-new issues and revisiting older concepts and topics.

\section{Declaration of Competing Interest}

None declared.

\section{References}

Abrar-ul-Hassan, S., Douglas, D., \& Turner, J. (2021). Revisiting second language portfolio assessment in a new age. System, 103. https://doi.org/10.1016/j.system.2021.102652

Ahlburg, D.A. (2020). Covid-19 and UK Universities. The Political Quarterly, 91(3), 649-654. https://doi. org/10.1111/1467-923X.12867

Al-Salman, S., \& Haider, A. S. (2021). Covid-19 trending neologisms and word formation processes in English. Russian Journal of Linguistics, 25(1), 24-42. https://doi.org/10.22363/2687-0088-2021-25-1-24-42

Almusharraf, N. M., \& Khahro, S. H. (2020). Students' satisfaction with online learning experiences during the Covid-19 pandemic. International Journal of Emerging Technologies in Learning, 15(21), 246-267. https://doi. org/10.3991/ijet.v15i21.15647

Asif, M., Zhiyong, D., Iram, A., \& Nisar, M. (2021). Linguistic analysis of neologism related to coronavirus (Covid-19). Social Sciences \& Humanities Open, 4(1), 100201. https://doi.org/10.1016/j.ssaho.2021.100201

Bao, W. (2020). Covid-19 and online teaching in higher education: A case study of Peking University. Human Behavior and Emerging Technologies, 2, 113 - 115. https://doi.org/10.1002/hbe2.191

Charania, A., Bakshani, U., Paltiwale, S., Kaur, I., \& Nasrin, N. (2021). Constructivist teaching and learning with technologies in the Covid-19 lockdown in eastern India. British Journal of Educational Technology, 52(4), 1478-1493. https://doi.org/10.1111/bjet.13111

Cheung, A. (2021). Language teaching during a pandemic: A case study of zoom use by a secondary ESL teacher in Hong Kong. RELC Journal. https://doi.org/10.1177/0033688220981784

Choi, L., \& Chung, S. (2021). Navigating online language teaching in uncertain times: Challenges and strategies of EFL educators in creating a sustainable technology-mediated language learning environment. Sustainability, 13(14), 7664. https://doi.org/10.3390/su13147664

Cierpich-Kozieł, A. (2020). Corona reality - about new Polish compound words with the stem korona-in the time of pandemic. Jezyk Polski, 100(4), 102-117. https://doi.org/10.31286/JP.100.4.7

Gregersen, T., Mercer, S., \& MacIntyre, P. D. (2021). Language teacher perspectives on stress and coping. Foreign Language Annals, 1-19. https://doi.org/10.1111/flan.12544

Haddad, A. H., \& Montero-Martínez, S. (2020). Covid-19: A metaphor-based neologism and its translation into Arabic. Journal of Science Communication, 19(5), 1-21. https://doi.org/10.22323/2.19050201

Hazaea, A. N., Bin-Hady, W. R. A., \& Toujani, M. M. (2021). Emergency remote English language teaching in 
the Arab league countries: Challenges and remedies. Computer Assisted Language Learning Electronic Journal, 22(1), 207-229.

Heydarnejad, T., Zareian, G., Ghaniabadi, S., \& Adel, S. M. R. (2021). Measuring language teacher emotion regulation: Development and validation of the language teacher emotion regulation inventory at workplace (LTERI). Frontiers in Psychology, 12, 3345. https://doi.org/10.3389/fpsyg.2021.708888

Ionela, I. (2020). How to adapt your ESP course to e-learning resources and tools. Journal of Higher Education Theory and Practice, 20(16), 128-135. https://doi.org/10.33423/jhetp.v20i16.3996

Jablonka, E. (2021). The influence of the lexeme "coronavirus" in the Polish and Portuguese lexicon. Etudes Romanes De Brno, 42(1), 123-140. ttps://doi.org/10.5817/ERB2021-1-7

Lei, S., Yang, R., \& Huang, C. (2021). Emergent neologism: A study of an emerging meaning with competing forms based on the first six months of Covid-19. Lingua, 258, 103095. https://doi.org/10.1016/j.lingua.2021.103095

Levina, V., Zubanova, S., \& Ivanov, A. (2021). Axiological linguistics and teaching of Russian as a foreign language in the context of distance learning against the backdrop of the pandemic. XLinguae, 14(1), 212-227. https://doi.org/10.18355/XL.2021.14.01.17

Mahapatra, S. K. (2021). Online formative assessment and feedback practices of ESL teachers in India, Bangladesh and Nepal: A multiple case study. Asia-Pacific Education Researcher, 30(6), 519-530. https://doi.org/10.1007/ s40299-021-00603-8

Moser, K. M., Wei, T., \& Brenner, D. (2021). Remote teaching during Covid-19: Implications from a national survey of language educators. System, 97, 102431. https://doi.org/10.1016/j.system.2020.102431

Reimers, F. M. (Ed.). (2022). Primary and secondary education during Covid-19. Disruptions to educational opportunity during a pandemic. Springer. https://doi.org/10.1007/978-3-030-81500-4

Reimers, F. M., \& Marmolejo, F. (Eds.). (2022). University and school collaborations during a pandemic. Knowledge Studies in Higher Education. Springer. https://doi.org/10.1007/978-3-030-82159-3

Resnik, P., \& Dewaele, J. (2021). Learner emotions, autonomy and trait emotional intelligence in 'in-person' versus emergency remote English foreign language teaching in Europe. Applied Linguistics Review. https:// doi.org/10.1515/applirev-2020-0096

Tabatadze, S., \& Chachkhiani, K. (2021). Covid-19 and emergency remote teaching in the country of Georgia: Catalyst for educational change and reforms in Georgia? Educational Studies - AESA, 57(1), 78-95. https://doi. org/10.1080/00131946.2020.1863806

Teixeira da Silva, J. A., \& Al-Khatib, A. (2021). How do clarivate analytics and publons propose to fortify peer review in the Covid-19 era? Journal of Taibah University Medical Sciences, 16(2), 139-143. https://doi. org/10.1016/j.jtumed.2021.01.008

Thaheem, S. K., Zainol Abidin, M. J., Mirza, Q., \& Pathan, H. U. (2021). Online teaching benefits and challenges during pandemic Covid-19: A comparative study of Pakistan and Indonesia. Asian Education and Development Studies. https://doi.org/10.1108/AEDS-08-2020-0189

Wang, X., \& Huang, C. (2021). From contact prevention to social distancing: The co-evolution of bilingual neologisms and public health campaigns in two cities in the time of Covid-19. SAGE Open, 11(3). https://doi. org/10.1177/21582440211031556

Wong, K. M., \& Moorhouse, B. L. (2021). Digital competence and online language teaching: Hong Kong language teacher practices in primary and secondary classrooms. System, 103, 102653. https://doi.org/10.1016/j. system.2021.102653

Zholobova, A. (2021). Linguistic innovation during the Covid-19 pandemic: The Spanish language case. XLinguae, 14(2), 331-349. https://doi.org/10.18355/XL.2021.14.02.24 